\title{
Speciation of Fe(II) and Fe(III) in Geological Samples by Solvent Extraction and Flame Atomic Absorption Spectrometry (FAAS)
}

\author{
Susanta Kumar Pradhan ${ }^{\mathrm{a}, *}$, Balram Ambade ${ }^{\mathrm{b}}$, and Pranab Kumar Tarafder ${ }^{\mathrm{a}}$ \\ a Chemical Laboratory, Atomic Minerals Directorate for Exploration and Research, \\ Department of Atomic Energy, Eastern Region, Khasmahal, Jamshedpur 831002, India \\ ${ }^{b}$ Department of Chemistry, National Institute of Technology, Jamshedpur 831014, India
}

\section{INTRODUCTION}

Iron $(\mathrm{Fe})$ is one of the most common metallic elements found in the earth's crust. Determination of the $\mathrm{Fe}(\mathrm{II})$ and $\mathrm{Fe}$ (III) species is of great importance in geological, biological and environmental materials due to the specific role of their oxidation states. The analysis of ferrous oxides in rocks and minerals is of great interest to petrologists and mineralogists (1). The ratio of ferrous to ferric oxide plays an important role not only in interpreting geological data, but also in determining the redox condition of iron in natural water. It is an essential nutritional element for all life forms, i.e., a cofactor in many enzymes and essential for oxygen transport and electron transfer (2). Hence, it is very important from an analytical point of view to develop a sensitive, selective, and rapid method for the quantitative determination of ferrous and ferric iron present in various materials.

There are several individual methods for the determination of ferrous oxide (3-7) as well as ferric oxide (8). However, very few methods are available for the simultaneous or sequential determination of both oxides in geological samples such as rocks, soils, cores, stream sediments, minerals, etc. In general, Pratt's titrimetric method using dichromate as a titrant has been used for the determination of ferrous oxides in geological samples. However, this particular method

Corresponding autbor.

E-mail: skpradban.amd@gov.in

\section{ABSTRACT}

A procedure has been devised for the selective determination of ferrous and ferric oxides in geological samples such as rocks, soils, cores, stream sediments, etc. This is based on the selective dissolution of both oxides with an ammonium bi-fluoride and sulfuric acid mixture, followed by solvent extraction separation of Fe(III) into ethyl acetate using thiocyanate. The extracted Fe(III) was stripped off into dilute hydrochloric acid solution and determined by flame atomic absorption spectrometry (FAAS). $\mathrm{Fe}(\mathrm{II})$ in the aqueous solution was determined by FAAS separately. The method was applied to a number of geological samples including certified reference materials (CRMs) and synthetic mixtures. The results obtained by the proposed method for the CRMs were found to be in excellent agreement with the reported values. Similarly, the results of a set of geological samples were comparable with those obtained by the colorimetric method involving 1,10-orthophenanthrolene and the standard titrimetric (Pratt's) method.

has its limitations when applied to samples containing ferrous oxide at the parts per million (ppm) levels. A variety of colorimetric methods have been employed for the determination of ferrous and ferric ions in sample solution. The reagent 1,10-phenanthrolene has been extensively used in the colorimetric determination of ferrous iron and total iron after the reduction of fer- ric iron by chemical means or by photochemical reduction. Several authors applied 1,10-phenanthrolene to determine ferrous and total iron. However, the major concern of the method is the instability of the color. Stuky and Anderson (9) identified several sources of error in the 1,10-phenanthrolene method. One of the errors is the falsely high ferrous value due to photo-reduction of ferric to ferrous ions in the presence of 1,10 phenanthrolene with ordinary fluorescence light. They corrected this problem in the ferrous analysis by conducting the digestion and dilution steps under red light (typical dark room) condition. They obtained reliable results for ferrous, even in the presence of ferric ion, after conducting the experiment in typical dark room conditions. Many other workers have tried to improve the spectrophotometric method for ferrous and ferric ion determination by carrying out the reaction in dark room conditions. Recently, Tarafder and Thakur (10) reported that the error in the determination of ferrous ion in the presence of ferric ion is not due to the reduction of ferric ion into ferrous iron by any fluorescence light. Instead, the reason was assigned to the presence of organic matter in the sample solution which is responsible for the reduction of ferric to ferrous ion over time. Most of the methods used for the sequential determination of ferrous and ferric ion with 1,10-phenanthrolene are not able to yield accurate results.

In view of the above, an atomic absorption spectrometry (AAS) method has been devised to 
accurately estimate the ferrous and ferric ions sequentially; thus eliminating all of the limitations associated with the earlier reported methods. This novel scheme is based on the ammonium bi-fluoride dissolution of the sample in the presence of sulfuric acid, followed by the selective extraction of the ferric ions into ethyl acetate as thiocyanate complexes. The Fe(III) ions were then stripped off into diluted $\mathrm{HCl}$ solution and determined by flame AAS. Glokas et al. (11) have worked on the speciation of ferrous and ferric ions in water samples by flame AAS after cloud point microextraction. Their method involves cloud point extraction (CPE) of both species with ammonium pyrrolidinecarbodithioate (APDC) under standard conditions, which facilitates the in situ complexation and extraction of both species. They used mathematical equations to overcome the interference of $\mathrm{Fe}$ (III) in the spectrometric determination of Fe(II) present in the same sample solution. However, they used ferrozine which has the disadvantages of reducing Fe(III) to $\mathrm{Fe}(\mathrm{II})$, unless Fe(III) is sequestered with fluoride or EDTA. Therefore, the presence of fluoride is advisable in the ferrozine method. Speciation of ferrous and ferric ions in combination with solvent extraction/solid phase extraction and FAAS in water, fruit juice, cola, tea infusion, etc., has also been reported in the literature (12-13).

In the proposed method, the ferrous and ferric ions are leached out into the solution with an ammonium bi-fluoride and sulfuric acid treatment. Fe(III) in solution forms a strong fluorosulfate complex, and extraction of the ferric ion bound in this complex is not possible unless Fe(III) is freed by breaking the complex. However, when boric acid is added, the complex is broken due to the formation of a strong $\mathrm{H}\left[\mathrm{BF}_{4}\right]$ complex, and immediately Fe(III) is released in the solution and can be extracted as thiocyanate complex into the organic solvent, such as ethyl acetate, leaving the Fe(II) ions in solution, which does not form a similar fluorosulfate complex as formed by Fe(III). This way the ferric ion is separated from the ferrous ion. Fe(III) is stripped off from the organic solvent into the diluted $\mathrm{HCl}$ medium and determined by FAAS. $\mathrm{Fe}(\mathrm{II})$ in aqueous solution can be directly estimated by aspirating into the FAAS. This way, both Fe(II) and $\mathrm{Fe}$ (III) in the aqueous solution can be determined selectively and sequentially in the geological samples. It is important to mention that the ferric fluorosulfate or trifluorosulfato ferrate(III) $\left[\mathrm{Fe}^{\mathrm{III}}\left(\mathrm{SO}_{4}\right) \mathrm{F}_{3}\right]^{2-}$ complex had been synthesized earlier by Chaudhury and Islam (14).

The proposed method is a novel approach for the speciation of ferrous and ferric oxides in geological samples such as rocks, soils, cores, and stream sediments, and to the best of the authors' knowledge, speciation of iron by this proposed technique has not been reported in the literature and is based on the following reaction scheme:

$$
\begin{aligned}
& \mathrm{NH}_{4} \mathrm{HF}_{2}=\mathrm{NH}_{4} \mathrm{~F}+\mathrm{HF} \\
& \mathrm{Fe}_{2} \mathrm{O}_{3}+6 \mathrm{HF}=2 \mathrm{FeF}_{3}+3 \mathrm{H}_{2} \mathrm{O} \\
& \mathrm{FeF}_{3}+\mathrm{H}_{2} \mathrm{SO}_{4}+2 \mathrm{NH}_{4} \mathrm{~F}= \\
& \left(\mathrm{NH}_{4}\right)_{2}\left[\mathrm{Fe}^{\mathrm{III}}\left(\mathrm{SO}_{4}\right) \mathrm{F}_{3}\right]+2 \mathrm{HF}
\end{aligned}
$$

$$
\begin{aligned}
& 4\left(\mathrm{NH}_{4}\right)_{2}\left[\mathrm{Fe}^{\mathrm{III}}\left(\mathrm{SO}_{4}\right) \mathrm{F}_{3}\right]+3 \mathrm{H}_{3} \mathrm{BO}_{3} \\
& +6 \mathrm{H}_{2} \mathrm{SO}_{4}=4\left(\mathrm{NH}_{4}\right)_{2} \mathrm{SO}_{4}+ \\
& 2 \mathrm{Fe}_{2}\left(\mathrm{SO}_{4}\right)_{3}+3 \mathrm{H}\left[\mathrm{BF}_{4}\right]+9 \mathrm{H}_{2} \mathrm{O}(\mathrm{iv}) \\
& \mathrm{Fe}^{3+}+6 \mathrm{SCN}^{-}=\left[\mathrm{Fe}(\mathrm{SCN})_{6}\right]^{3-}(\mathbf{v})
\end{aligned}
$$

Using this approach, most of the earlier drawbacks found by using photochemical reduction or reduction due to organic matter can be completely eliminated.

\section{EXPERIMENTAL}

\section{Instrumentation}

For this study, a ZEEnit 700 flame atomic absorption spectrometer (Analytik Jena, Germany) was used for measurement of the absorbance of iron. An iron hollow cathode lamp (HCL) was used for the light source. Details of the optimum instrumental operating conditions are listed in Table I.

A Specord 250+ double-beam UV-visible spectrophotometer (Analytik Jena, Germany) with a $1 \mathrm{~cm}$ path length quartz cell was used for the absorbance measurements of the iron-phenanthrolene color complex at $\lambda=560 \mathrm{~nm}$.

An Ultima-2 inductively coupled plasma optical emission spectrometer (Horiba Scientific, Yobin Yvon Technology, France) was also used for the determination of total iron at the wavelength of $259.940 \mathrm{~nm}$.

TABLE I

\section{Optimum FAAS Instrumental Operating Conditions}

$\begin{array}{lr}\text { Light source } & \text { Iron Hollow Cathode Lamp (HCL) } \\ \text { Wave Length } & 248.3 \mathrm{~nm} \\ \text { Slit width } & 0.5 \mathrm{~nm} \\ \text { Lamp current } & 5.0 \mathrm{~mA} \\ \text { Atomizer } & 100 \mathrm{~mm} \text { slot burner } \\ \text { Back ground correction } & \text { Deuterium lamp background } \\ \text { Fuel } & \text { Acetylene } \\ \text { Support } & \text { Air } \\ \text { Flame stoichiometry } & \text { Oxidizing } \\ \text { Calibration curve } & \text { Five point calibration curves }\left(1-10 \mu \mathrm{mL}^{-1}\right) \\ \text { No. of replicates for measurement } & 4\end{array}$


A laboratory stirrer with a glass ceramics heater and temperature sensor was used for the leaching studies.

\section{Standard Solution and Reagents}

Specpure ${ }^{\circledR}$ standard solution of iron $(1000 \mu \mathrm{g} \mathrm{mL}-1)$ (Alfa Aesar, USA) in $5 \% \mathrm{HNO}_{3}$ was used as a standard stock solution. The working standard solutions (1-10 $\mu \mathrm{g} \mathrm{mL}^{-1}$ ) were prepared by diluting the standard stock solution with distilled water.

Unless otherwise stated, all reagents used were of analytical/ guaranteed grade.

\section{Recommended Procedure}

\section{Preparation of Sample Solution}

A finely crushed sample of $0.2 \mathrm{~g}$ (-200\#) was transferred to a clean Teflon $^{\circledR}$ beaker (125 mL capacity), and $1.0 \mathrm{~g}$ solid $\mathrm{NH}_{4} \mathrm{HF}_{2}$ and $10 \mathrm{~mL}$ of $1: 1 \mathrm{H}_{2} \mathrm{SO}_{4}$ added. The beaker was covered with a Teflon lid and heated to about $70-80{ }^{\circ} \mathrm{C}$ on a hotplate for 15-20 minutes. Then the beaker was removed and cooled to room temperature. The content of the Teflon beaker was transferred into a $50 \mathrm{~mL}$ volumetric (plastic) flask and made up to volume with distilled water.

\section{Extraction of Fe(III) as Fe(III)- Thiocyanate Complex}

An aliquot ( 1 to $5 \mathrm{~mL}$ ) of sample solution depending on the iron concentration was taken into a $100 \mathrm{~mL}$ separating funnel. Approximately $1.0 \mathrm{~g}$ boric acid powder was added and mixed thoroughly for 2 minutes. Then $5 \mathrm{~mL}$ of $10 \% \mathrm{KCNS}$ (w/v) solution and $10 \mathrm{~mL}$ ethyl acetate were added, and shaken for 2-3 minutes. The resulting color complex of $\mathrm{Fe}$ (III) thiocyanate was extracted into the organic layer. The aqueous layer was separated out into a $100 \mathrm{~mL}$ beaker. Fe(III) in the organic layer was stripped off using $10 \mathrm{~mL} \mathrm{5 \%} \mathrm{HCl}(\mathrm{v} / \mathrm{v})$ solution, then placed into a $50 \mathrm{~mL}$ volumet- ric flask, and made up to the mark with distilled water.

\section{Determination of $\mathrm{Fe}$ (II) and Fe(III) by Flame AAS}

$\mathrm{Fe}(\mathrm{II})$ in the aqueous layer (which was kept in a $100 \mathrm{~mL}$ beaker) was transferred into a $50 \mathrm{~mL}$ volumetric flask and made up to volume with distilled water. Direct measurement of Fe(II) was carried out by aspirating the solution into the FAAS. Similarly, the extracted Fe(III) in the separated solution was also determined by aspiration into the FAAS. In both cases, the absorbances of iron were measured using a calibration curve prepared by absorbance against the standard iron solutions ( 1 to 10 $\left.\mu \mathrm{g} \mathrm{mL}{ }^{-1}\right)$. A blank was also run in a similar manner.

\section{RESULTS AND DISCUSSION}

As has already been discussed above, the titrimetric determination of ferrous oxide based on using the $\mathrm{Fe}(\mathrm{II}) / \mathrm{Fe}$ (III) dichromate/permanganate redox system for geological samples (rocks, soils, and stream sediments) is very difficult, particularly at trace levels, i.e., the ppm levels. Similarly, determination of ferrous oxide in rock samples by UV-visible spectrometry using the reagent orthophenanthrolene and ferrozine is also not free from errors due to several reasons (9-11). In order to eliminate the abovementioned drawbacks, the authors devised a system for the accurate and sequential determination of ferrous and ferric oxides in all types of geological samples, particularly rocks, soils, and stream sediments, by FAAS.

The main advantages of FAAS for the determination of metal ions are speed and high selectivity. It is also a moderately sensitive technique for some transition elements, including iron. However, determination of ferrous ions in geological samples, particularly rocks, soils, and stream sediments by FAAS, to the best of the authors' knowledge have so far not been reported in the literature. In this paper, a robust and reliable method for the determination of both ferrous and ferric oxide in most geological samples is described. The method is based on the rapid leaching of ferrous and ferric ions using a combination of $\mathrm{H}_{2} \mathrm{SO}_{4}$ and $\mathrm{NH}_{4} \mathrm{HF}_{2}$ at a moderate temperature $\left(70-80^{\circ} \mathrm{C}\right)$ as per the procedure described in the literature (10). Of the ferrous and ferric ions leached into the solution after $\mathrm{H}_{2} \mathrm{SO}_{4} / \mathrm{NH}_{4} \mathrm{HF}_{2}$ treatment, $\mathrm{Fe}(\mathrm{III})$ rapidly forms a strong fluorosulfate complex (14) leaving ferrous ions free in the solution. The ferric ion strongly bound in the mixed ligand ternary fluorosulfate complex is released into the solution on the breach of the said ternary complex by the addition of boric acid, which has stronger affinity towards fluoride ions bound in the complex. The released ferric ion reacts with potassium thiocyanate forming the ferric thiocyanate complex, which is easily extracted into ethyl acetate leaving the ferrous ions in the leached solution. The ferric ion bound in the extracted thiocyanate complex was stripped off into the diluted $\mathrm{HCl}$ solution and measured by FAAS. The ferrous ion present in the aqueous solution after separation of the ferric ions by solvent extraction was directly measured by FAAS. In this way, both ferrous and ferric ions are determined by FAAS.

A mixture of $10 \mathrm{~mL}$ of (1:1) $\mathrm{H}_{2} \mathrm{SO}_{4}$ and $1 \mathrm{~g} \mathrm{NH}_{4} \mathrm{HF}_{2}$ at $70-80{ }^{\circ} \mathrm{C}$ for about 15-20 minutes are the optimum conditions for leaching the ferrous and ferric ions for $0.2 \mathrm{~g}$ geological samples. The details of effect of such variables as the effects of acid and salt $\left(\mathrm{H}_{2} \mathrm{SO}_{4}\right.$ and $\mathrm{NH}_{4} \mathrm{HF}_{2}$ ), time and temperature on the leaching of both oxides are discussed in the literature (10). However, the effects of other variables 
such as the effect of boric acid, thiocyanate concentration, choice of solvent, effects of stripping agents, etc., are discussed below.

\section{Effects of Boric Acid}

Boric acid is used to release $\mathrm{Fe}(\mathrm{III})$ from a strong fluorosulfate complex of $\mathrm{Fe}(\mathrm{III})$ at the prevailing reaction condition, i.e., in a strong $\mathrm{H}_{2} \mathrm{SO}_{4}$ medium. The ferric ions strongly bound in the mixed ligand ternary fluorosulfate complex are released into the solution on the breach of the said ternary complex by the addition of boric acid, which has a stronger affinity towards fluoride ions forming the $\mathrm{H}\left[\mathrm{BF}_{4}\right]$ complex. This aspect was also ascertained by the addition of thiocyanate solution without addition of boric acid. Formation of no red color solution of ferric thiocyanate indicates that the leached Fe(III) ions are not available in the solution to form a complex with thiocyanate ions; instead, they formed the ternary fluorosulfate complex. The effect of boric acid on the release of Fe(III) ions from the ternary fluorosulfate complex was studied for boric acid concentrations ranging from 0.1 to $5 \mathrm{~g}$ for $1 \mathrm{~mL}$ leached solution of certified reference material (SY-3) from the Canadian Certified Reference Materials Project (CCRMP). An amount of $0.5 \mathrm{~g}$ boric acid is sufficient to mask fluoride ions present in the solution. However, in order to allow for impurities, present in the reagent as well as to allow for the extra consumption of the reagent by the matrix elements present in the sample solution, a $1 \mathrm{~g}$ boric acid was found to be optimum for $99 \%$ recovery of ferric ions. This is illustrated in Figure 1.

\section{Effects of Thiocyanate Concen- tration on the Extraction of Ferric Ions}

Iron(III) reacts with thiocyanate and results in a series of intensely red colored complexes,

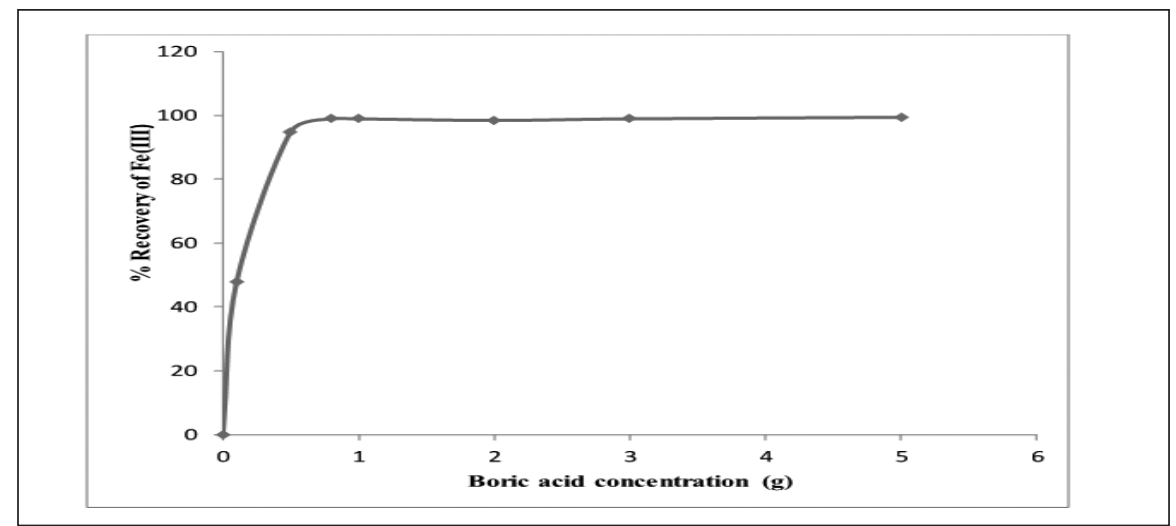

Fig. 1 Effect of boric acid concentration ( $g$ ) on the release of Fe(III) from its fluorosulfate complex.

TABLE II

Recovery of Fe(II) and Fe(III) in Synthetic Mixtures

\begin{tabular}{cccccc}
\hline $\begin{array}{c}\text { Fe(II) } \\
\text { Taken } \\
(\mu \mathrm{g})\end{array}$ & $\begin{array}{c}\text { Fe(II) } \\
\text { Found } \\
(\mu \mathrm{g})\end{array}$ & $\begin{array}{c}\text { Recovery } \\
(\%)\end{array}$ & $\begin{array}{c}\text { Fe(III) } \\
\text { Taken } \\
(\mu \mathrm{g})\end{array}$ & $\begin{array}{c}\text { Fe(III) } \\
\text { Found } \\
(\mu \mathrm{g})\end{array}$ & $\begin{array}{c}\text { Recovery } \\
(\%)\end{array}$ \\
\hline 50 & 47 & 94 & 200 & 214 & 107 \\
100 & 95 & 95 & 150 & 162 & 108 \\
150 & 190 & 95 & 100 & 110 & 110 \\
200 & 142 & 95 & 50 & 55 & 110 \\
\hline
\end{tabular}

${ }^{\mathrm{a}}$ For Fe(II), salt used ammonium ferrous sulfate hexahydrate (GR, Merck).

${ }^{\mathrm{b}}$ For Fe(III), salt used ammonium ferric sulfate dodecahydrate (GR, Merck).

which remain in solution. Iron(II) does not react. Depending on the thiocyanate concentration, a series of complexes can be obtained, which are red in color and can be formulated as $[\mathrm{Fe}(\mathrm{SCN}) \mathrm{n}]^{3-\mathrm{n}}$, where $n=1, \ldots, 6$. At low thiocyanate concentration, the predominant colored species is $[\mathrm{Fe}(\mathrm{SCN})]^{2+}$, whereas at $0.1 \mathrm{M}$ thiocyanate concentration it is largely $\left[\mathrm{Fe}(\mathrm{SCN})_{2}\right]^{+}$, while at very high thiocyanate concentration it is $\left[\mathrm{Fe}(\mathrm{SCN})_{6}\right]^{3-}$. In the colorimetric determination, a large amount of thiocyanate is used since it increases the intensity and stability of the color. Thiocyanate colorimetric determination of $\mathrm{Fe}$ (III) is a well-established method (15-16). A $5 \mathrm{~mL}$ of $2 \mathrm{M}$ thiocyanate solution (15) was used to form the Fe(III) thiocyanate complex for $1 \mathrm{~mL}$ leached solution of the synthetic mixtures under study. It was observed that the extraction of this ferric thiocyanate complex into ethyl acetate is quantitative (more than 99\% recovery) which is shown in Table II.

\section{Effects of Diverse Ions on the Extraction of the Fe(III)- Thiocyanate Complex}

The thiocyanate spectrometry method used for the determination of $\mathrm{Fe}$ (III) is reported in the literature (15-16). Hence, further studies on the effects of diverse ions for the formation of the ferric thiocyanate complex are redundant here. However, the effects of borate, fluoride, and sulfate ions were examined on the extraction of the ferric thiocyanate complex into ethyl acetate. Though sulfate ions have a tendency to form a complex with 
Fe(III), it has been observed that up to a 1000-fold excess concentration of sulfate ions had no effect on the extraction of the Fe(III) thiocyanate complex from the leach solution. Similarly, the fluoride ions, which have a tendency to form a complex with $\mathrm{Fe}(\mathrm{III})$, have been removed by masking these by the addition of excess boric acid. No adverse effect from the borate ions on the extraction of the Fe(III) thiocyanate complex in the leached solution was observed.

\section{Choice of Solvents}

Various solvents were tried for liquid-liquid extraction of the ferric thiocyanate complex. Mention is made of butanol, n-butylacetate, ethylacetate, di-ethylether, MIBK, carbon tetrachloride, hexane, benzene, toluene, etc. However, the extraction was found to be optimum with ethyl acetate. Similarly, several mineral acids were tried for stripping the ferric ions into the aqueous phase. A $10 \mathrm{~mL}$ of $5 \% \mathrm{HCl}(\mathrm{v} / \mathrm{v})$ solution was found to be optimum as the stripping solution.

\section{Validation, Accuracy and Precision}

In order to validate the method developed, and in order to attest the efficacy of the leaching and extractive system, the proposed method was applied to a set of synthetic mixtures and CRMs of rocks, soils, and stream sediment samples. To ascertain the accuracy and precision of the developed method, a set of synthetic mixtures having variable concentrations of $\mathrm{Fe}$ (II) and Fe(III) were prepared and analyzed. The recovery of Fe(II) and Fe(III) was more than $95 \%$ and $100 \%$, respectively (see Table II). Similarly, the CRM geo-standards of SY-3, SY-4, and MRG-1 from the Canadian Certified Reference Materials Project (CCRMP), DNC-1a, NKT-1 and sdAR-1 from the U. S. Geological Survey (USGS), and SARM-6 and SARM-48 from Mintek, South African Reference Material, were analyzed for ferrous and ferric oxides by the proposed method. The results for both oxides were in excellent agreement with the reported values and are shown in Table III. The nature of all of the above CRMs used are also listed in Table III. It is pertinent to mention that the reference materials NKT-1 and sdAR-1 were analyzed in this laboratory as a part of the 29th and 31 st round of Geo-PT programmes which are an International Association of Geo-analysts' Proficiency Testing Programme for Analytical Geochemistry Laboratories. There is only reported value for total $\mathrm{Fe}$ as $\mathrm{Fe}_{2} \mathrm{O}_{3}$ (T) for both the CRMs of NKT-1 and sdAR-1 instead of ferrous and ferric oxides separately. Hence, to calculate the total $\mathrm{Fe}$ as $\mathrm{Fe}_{2} \mathrm{O}_{3}(\mathrm{~T})$ by the proposed method, the following equation has been adopted:

$$
\begin{aligned}
& \% \mathrm{Fe}_{2} \mathrm{O}_{3}(\mathrm{~T})=\% \mathrm{FeO} \times 1.111+ \\
& \% \mathrm{Fe}_{2} \mathrm{O}_{3}
\end{aligned}
$$

where 1.111 is the conversion factor from $\mathrm{FeO}$ to $\mathrm{Fe}_{2} \mathrm{O}_{3}$. Based on the equation, the total $\mathrm{Fe}$ as \% $\mathrm{Fe}_{2} \mathrm{O}_{3}(\mathrm{~T})$ by the proposed method for NKT-1 and sdAR-1 are 13.38\% and $4.59 \%$ and are comparable with the reported value of $13.29 \%$ and $4.63 \%$, respectively. The proposed method yields fairly accurate results under the optimized conditions. The accuracy was found within $5 \%$ and $8 \%$ for ferrous and ferric oxides, respectively, and was calculated on the basis of reported values for the reference materials under study. The precision (\% RSD) of the method was found within $4 \%$ and $7 \%$ for the ferrous and ferric oxides, respectively, for four replicate determinations $(n=4)$. From the results listed in Tables II and III, it can be observed that there is a slightly higher value of ferric oxide, which may be due to the partial oxidation of ferrous oxide by air or any oxidizing agent present in the sample solution.

TABLE III

\begin{tabular}{|c|c|c|c|c|c|c|}
\hline \multirow[t]{2}{*}{ CRMs } & \multirow{2}{*}{$\begin{array}{l}\text { Nature of } \\
\text { Samples }\end{array}$} & \multicolumn{2}{|c|}{$\mathrm{FeO}(\%)$} & \multicolumn{2}{|c|}{$\mathrm{Fe}_{2} \mathrm{O}_{3}(\%)$} & \multirow{2}{*}{$\begin{array}{l}\text { Total } \mathrm{Fe} \text { as } \\
\mathrm{Fe}_{2} \mathrm{O}_{3}(\mathrm{~T}) \%\end{array}$} \\
\hline & & $\begin{array}{l}\text { Proposed } \\
\text { Method }^{\mathrm{a}}\end{array}$ & $\begin{array}{c}\text { Reported } \\
\text { Value }\end{array}$ & $\begin{array}{l}\text { Proposed } \\
\text { Method }^{\mathrm{a}}\end{array}$ & $\begin{array}{l}\text { Reported } \\
\text { Value }\end{array}$ & \\
\hline $\mathrm{SY} / 3$ & Synite & $3.54 \pm 0.15$ & 3.58 & $2.97 \pm 0.10$ & 2.84 & - \\
\hline $\mathrm{SY} / 4$ & Diorite & $2.84 \pm 0.16$ & 2.86 & $3.21 \pm 0.21$ & 3.03 & - \\
\hline MRG-1 & Gabbro & $8.18 \pm 0.30$ & 8.63 & $8.64 \pm 0.27$ & 8.48 & - \\
\hline DNC-1a & Dolerite & $7.02 \pm 0.28$ & 7.32 & $1.92 \pm 0.10$ & 1.79 & - \\
\hline NKT-1 & Nephelinite & $8.10 \pm 0.42$ & - & $4.38 \pm 0.22$ & - & 13.29 \\
\hline sdAR-1 & River sediment & $0.85 \pm 0.06$ & - & $3.65 \pm 0.20$ & - & 4.63 \\
\hline SARM-6 & Soil & $14.02 \pm 0.35$ & 14.63 & $0.76 \pm 0.10$ & 0.71 & - \\
\hline SARM-48 & Soil & $0.20 \pm 0.01$ & 0.21 & $0.63 \pm 0.06$ & 0.58 & - \\
\hline
\end{tabular}

Results of FeO and $\mathrm{Fe}_{2} \mathrm{O}_{3}$ by the Proposed FAAS Method in CRMs

${ }^{\text {a }}$ Mean of four replicate determinations with $95 \%$ confidence level. 


\section{Analytical Applications}

The proposed method was thoroughly applied to a set of rock, soil, and core samples received from the different parts of eastern India. The results of a few of these samples by the proposed extractive method are comparable to those obtained by other standard techniques, such as the colorimetric method involving 1,10-phenanthrolene as the complexing agent as per the procedure devised by Tarafder and Thakur (10) and the standard titrimetric method involving $\mathrm{K}_{2} \mathrm{Cr}_{2} \mathrm{O}_{7}$ as titrant (Pratt's method). One ICP-OES technique was also used for the determination of total iron at the wavelength of $259.940 \mathrm{~nm}$, and the results are listed in Table IV. The results shown in Tables II to IV imply that the method developed is quite effective in the leaching of $\mathrm{Fe}(\mathrm{II})$ and $\mathrm{Fe}(\mathrm{III})$, selective extraction of $\mathrm{Fe}(\mathrm{III})$ into organic solvent and accurate determination of both species by FAAS.

\section{CONCLUSION}

The proposed method of ferrous and ferric oxides determination in geological samples offers several advantages such as ability to determine $\mathrm{FeO}$ and $\mathrm{Fe}_{2} \mathrm{O}_{3}$ in ppm to percentage levels, sequentially determine both $\mathrm{FeO}$ and $\mathrm{Fe}_{2} \mathrm{O}_{3}$ from the same sample solution, the results are reproducible and reliable, costeffective and eco-friendly, and less prone to interference. The proposed ammonium bi-fluoride and sulfuric acid mixture offers an effective method for leaching of the ferrous and ferric ions in geological samples of rocks, soils, cores, sediments, etc. This mixture sequestered ferric ion by formation of its fluorosulfate complex, where reduction of ferric to ferrous is prevented and enables the separation of ferric ions as thiocyanate complex from ferrous ions by solvent extraction. The method is costeffective in terms of sample throughput because one bottle (500 g) of ammonium bi-fluoride is used for about 250 sample digestions, whereas only 50 samples are digested with the help of one bottle (500 mL) HF, which is almost three times more costly than solid ammonium bi-fluoride; it is also ecofriendly because solid ammonium bi-fluoride is less hazardous than HF which is a liquid; and it completely eliminates most of the earlier drawbacks in other spectrometric methods such as photochemical reduction or reduction due to organic matter of ferric to ferrous iron.

\section{ACKNOWLEDGMENT}

The authors express their sincere thanks and gratitude to the Directors, NIT, Jamshedpur, and AMD, Hyderabad, for their kind permission to do research work leading to a Ph.D. The authors are thankful to the Regional Director and Dy. Regional Director, AMD,

\section{TABLE IV}

Comparison of Results of $\mathrm{FeO}$ and $\mathrm{Fe}_{2} \mathrm{O}_{3}$ in Rock, Soil, and Core Samples With the Proposed FAAS and Other Standard Methods

\begin{tabular}{cccccccc}
\hline Sample & $\begin{array}{c}\text { Nature of } \\
\text { Sample }\end{array}$ & $\begin{array}{c}\text { Proposed } \\
\text { FAAS } \\
\text { Method }^{\mathrm{a}}\end{array}$ & $\begin{array}{c}\text { FeO (\%) } \\
1,10 \text { Phenan- } \\
\text { throlene }^{\text {Method }}\end{array}$ & $\begin{array}{c}\text { Standard } \\
\text { Titrimetric }_{\text {Method }^{\mathrm{d}}}\end{array}$ & $\begin{array}{c}\text { Proposed } \\
\text { FAAS } \\
\text { Method }^{\mathrm{a}}\end{array}$ & $\begin{array}{c}\mathrm{Fe}_{2} \mathrm{O}_{3}(\%) \\
1,10 \text { Phenan }_{\text {throlene }} \\
\text { Method }^{\mathrm{c}}\end{array}$ & $\begin{array}{c}\text { ICP-OES } \\
\text { Method }^{\mathrm{b}}\end{array}$ \\
\hline JCL-1 & Rock & $0.20 \pm 0.01$ & 0.18 & 0.26 & $5.15 \pm 0.22$ & 5.27 & 5.30 \\
JCL-2 & Rock & $1.25 \pm 0.08$ & 1.30 & 1.40 & $3.64 \pm 0.14$ & 3.57 & 3.72 \\
JCL-3 & Rock & $2.15 \pm 0.20$ & 2.12 & 2.00 & $8.75 \pm 0.40$ & 8.80 & 8.50 \\
JCL-4 & Rock & $0.78 \pm 0.06$ & 0.72 & 0.70 & $1.72 \pm 0.08$ & 1.78 & 1.65 \\
JCL-5 & Soil & $7.58 \pm 0.28$ & 7.42 & 7.85 & $3.11 \pm 0.12$ & 3.25 & 3.18 \\
JCL-6 & Soil & $10.15 \pm 0.46$ & 10.02 & 10.50 & $5.52 \pm 0.20$ & 5.40 & 5.65 \\
JCL-7 & Soil & $5.90 \pm 0.24$ & 5.82 & 6.20 & $4.27 \pm 0.16$ & 4.50 & 4.32 \\
JCL-8 & Core & $4.90 \pm 0.20$ & 4.76 & 5.15 & $7.17 \pm 0.24$ & 7.02 & 7.28 \\
JCL-9 & Core & $1.78 \pm 0.10$ & 1.73 & 1.65 & $0.78 \pm 0.04$ & 0.70 & 0.65 \\
JCL-10 & Core & $1.10 \pm 0.06$ & 1.15 & 1.25 & $1.30 \pm 0.06$ & 1.22 & 1.40. \\
\hline
\end{tabular}

${ }^{\text {a }}$ Mean of four replicate determinations with $95 \%$ confidence level.

b $\% \mathrm{Fe}_{2} \mathrm{O}_{3}=\left[\% \mathrm{Fe}\left(\right.\right.$ Total) - \% Fe(II)] x 1.429 (conversion factor from FeIII to $\mathrm{Fe}_{2} \mathrm{O}_{3}$ ).

c Optimized ortho-phenanthrolene method (10).

${ }^{\mathrm{d}} \mathrm{K}_{2} \mathrm{Cr}_{2} \mathrm{O}_{7}$ as titrant (Pratt's method). 
Eastern Region, Jamshedpur, for providing the necessary facilities to carry out this work. The authors are also thankful to the Head, Chemistry Group, AMD, Hyderabad, and Dr. Vijay Kumar, Incharge, Chemistry Laboratory, AMD, Jamshedpur, for their constant encouragement, support, and motivation to do the work.

Received March 26, 2019.

\section{REFERENCES}

1. P. Komadel and J. W. Stucki, Clays and Clay Minerals 36(4), 379 (1988).

2. S. Pehkonen, The Analyst 120(11), 2655 (1995)

3. C. B. Brae and N. W. Bower, Geostandards and Geoanalytical Research 11(1), 41 (1987).
4. H. Hong and D. R. Kester, Limnology and Oceanography 31(3), 512 (1986)

5. G. Zhuang, Z. Yi, R. A. Duce and P. R. Brown, Nature 355(6360), 537 (1992).

6. J. E. Amonette and J. Matyas, Anal. Chim. Acta 910, 25(2015).

7. D. Xue, H. Wang, Y. Liu, L. Xie and P. Shen, Geostandards and Geoanalytical Research 43(3), 411 (2017).

8. J. E. Amonette and J. C. Templeton, Clays and Clay Minerals 46(1), 51 (1998).

9. J. W. Stucki, and W. L. Anderson, Soil Science Society of America Journal 45(3), 633 (1981).

10. P. K. Tarafder and R. Thakur, Geostandards and Geoanalytical Research 37(2), 155 (2013).

11. D. Giokas, E. K. Paleologos and M. Karayannis, Analytical and Bioanalytical Chemistry 373(4-5), 237 (2002).
12. E. Pehlivan and D. Kara, Microchim. Acta 158(1-2), 137 (2007).

13. M. Yaman and G. Kaya, Anal. Chim. Acta 540, 77 (2005).

14. M. K. Chaudhuri and N. S. Islam, Inorganic Chem. 25(21), 3749 (1986).

15. G. H. Jeffery, J. Basset, J. Mendhan, and R. C. Denney, Vogel's Textbook of Quantitative Chemical Analysis, 5th edn. ELBS, Longman Group, UK (1989).

16. H. Onishi, Photometric determination of trace metals, part IIB, Wiley, New York, USA (1989).

\section{* CRC Press/Taylor \& Francis announces the availability of}

\section{Measuring Elemental Impurities in Pharmaceuticals: A Practical Guide}

\section{Robert J. Thomas, CSci, CChem, FRSC Principal Consultant Scientific Solutions Gaithersburg, MD}

- The complete guide to measuring elemental impurities in pharmaceutical and nutraceutical materials.

- Covers heavy metals testing in the pharmaceutical industry from an historical perspective.

- Gives an overview of current USP Chapters $<232><233>$ and $<2232>$ and ICH Q3D Step 4 Guidelines.

- Explains the purpose of validation protocols used in Chapter <233>, including how J-values are calculated

- Describes fundamental principles and practical capabilities of ICP-MS and ICP-OES.

- Offers guidelines about the optimum strategy for risk assessment. - Provides tips on how best to prepare and present your data for regulatory inspection.

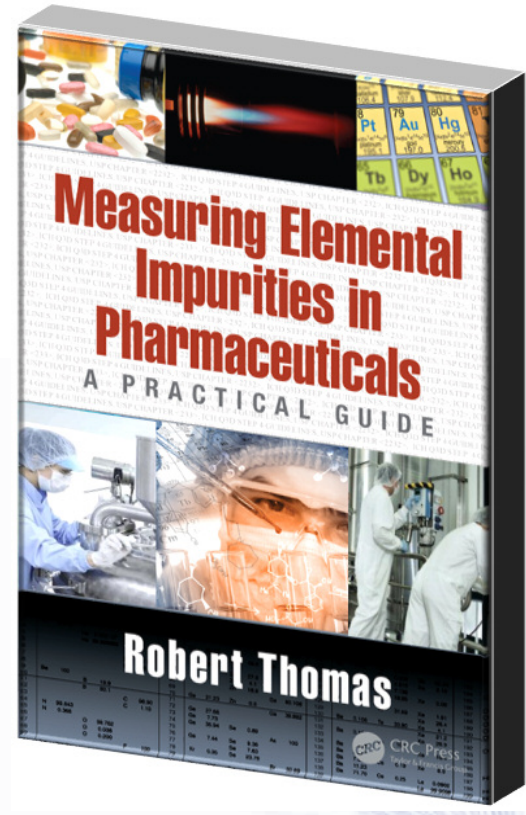

